\title{
The results of the first hydroacoustic studies of the winter distribution of Coregonus migratorius in Lake Baikal
}

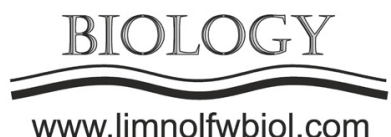

\author{
Anoshko P.N., Makarov M.M., Smolin I.N.*, Dzyuba E.V. \\ Limnological Institute of the Siberian Branch of the Russian Academy of Sciences, Ulan-Batorskaya 3, 664033 Irkutsk, Russia.
}

\begin{abstract}
We have obtained the first data on the distribution and behaviour of $C$. migratorius using the hydroacoustic recording of fish in the monostatic mode from the ice cover of Lake Baikal. The results of the studies have shown the nature of the winter distribution of $C$. migratorius, which also persists in the early spring. We assume that $C$. migratorius simultaneously executes three behavioural strategies. Observations of the $C$. migratorius behaviour in winter using the hydroacoustic method can be useful for the future studies of the characteristics of different behavioural and nutritional models as well as the age and size structure of populations inhabiting various zones of the lake. This approach, as a basis of the quantitative method of automatic recording of individual behavioural acts and changes in the fish aggregation, together with the use of hydrophysical equipment can show the response of fish to the changes in certain environmental parameters.
\end{abstract}

Keywords: Coregonus migratorius, hydroacoustic method, winter distribution, behaviour, Lake Baikal

\section{Introduction}

The seasonal dynamics characteristics of the Coregonus migratorius (Georgi, 1775) aggregations are relatively well-known and from the basis of fishing strategy (Kozhov, 1954; Smirnov and Shumilov, 1974; Melnik et al., 2009). The nature of the distribution and seasonal dynamics of $C$. migratorius in Baikal makes it a perfect object for developing the fundamentals of hydroacoustic resource research technology. On the one hand, the distribution characteristics distinguish C. migratorius from other fish species of the coastal complex, which have a swim bladder. On the other hand, C. migratorius differs significantly from the pelagic Cottoidei without a swim bladder in the intensity of back-scattered acoustic energy.

Traditionally, the study of the fish distribution is based on net and trawl surveys as well as hydroacoustic methods. Since 1987, acoustic-trawl studies have been conducting at Lake Baikal, and up to date they remain one of the promising methods for assessing stocks (Dzyuba et al., 2018). However, acoustic-trawl surveys are available only during ice-free season. Moreover, the studies of the fish distribution should consider such factors as fishing gear selectivity, fish behavioural responses to the noise fields made by vessels (Gerlotto and Fréon, 1992), including trawling (Engas et al., 2000), which may cause errors in assessing fish stocks (Brehmer et al., 2019). Hydroacoustic recording in the monostatic mode, which is usually used to observe the spawning fish migrations under river conditions and behaviour of fish approaching and migrating downstream through hydroelectric power plants as well as to study diel behaviour and movement of fish under conditions of lakes and lowland rivers (Lucas and Baras, 2000), can partially solve the above problems. The characteristics of $C$. migratorius behaviour in winter are poorly studied. In this regard, the possibility to use the hydroacoustic recording of fish in the monostatic mode from the ice cover of the lake is of special interest. The aim of this study is to test the hydroacoustic method for studying the distribution and behaviour of C. migratorius in winter.

\section{Materials and methods}

The works were carried out from the ice from 26 to 30 March 2018 along the Lystvyanka settlement - Tankhoy settlement transect at five stations (Fig. 1 , Table 1). The stations were selected by the lack of published data on the characteristics of the winter distribution and the behaviour of $C$. migratorius.

Winter period at Lake Baikal lasts from January to March (Kaplina, 1974), during which there is inverse thermal stratification of water and ice cover. The thickness of the ice cover during the study period was $60-70 \mathrm{~cm}$. To install the acoustic transducer at each station, ice holes of $1 \times 1 \mathrm{~m}$ were made. The acoustic transducer was placed in the centre of the ice hole using the frame and immersed in water to the plane of the surface one.

*Corresponding author.

E-mail address: ursus.88@mail.ru (I.N. Smolin)

(C) Author(s) 2019. This work is distributed under the Creative Commons Attribution 4.0 License. 
The hydroacoustic recording was performed permanently at each station in the monostatic mode. A Furuno FCV1100 modernized sonar with singlebeam transducer was used. The sonar settings: $3 \mathrm{~ms}$ probe pulse duration of, $2 \mathrm{~Hz}$ frequency sound of, $28 \mathrm{kHz}$ low-frequency transducer of with a $24^{\circ}$ pattern at $-3 \mathrm{~dB}$ and $200 \mathrm{kHz}$ high-frequency transducer with a $12^{\circ}$ pattern at $-3 \mathrm{~dB}$. During the works at station No. 2, a single measurement of the vertical profile of hydrophysical characteristics was performed. The measurements were performed using the SBE25 CTD probe with an additional oxygen sensor.

\section{Results and discussion}

With each beaming, 0-10 targets, 3.3 on average, (Fig. 2) were recorded in the volume reverberation, excluding insoluble aggregations. Target strength (TS) varied within $(-37)-(-30) \mathrm{dB}$.

The size composition of the objects recorded by both beams was reconstructed from the values of the intensity of back-scattered acoustic energy based on two TS dependencies on the fish length available for fishing (Fig. 3). One dependency was obtained in situ based on the trawl catches (Kudryavtsev et al., 2005); another ex situ in the cage experiment (Makarov et al., 2018). The first equation is more preferable due to the fact that standard coefficient $a=20$ leads to abnormally large reconstructed lengths of fish (Melnik et al., 2009). In the study period, the specimens of $22-42 \mathrm{~cm}$ in length, with two modes of 27 and $33 \mathrm{~cm}$, represented C. migratorius. The age and size characteristics of $C$. migratorius imply that in the studied area there were specimens older than four years with modes of 6 and 9 years.

The nature of acoustic records during the daytime was similar at all stations. At each station, there were low fish aggregations. Such distribution is also typical of the early spring. The spring hydroacoustic surveys showed that in the open part of the lake above great depths of more than $400 \mathrm{~m}, C$. migratorius aggregations were ten times lower than in the main fishing areas adjacent to the deltas of the main spawning rivers. However, these small fish aggregations over the water area of more than 23 thousand $\mathrm{km}^{2}$ contribute significantly to the fishing stock (Melnik et al., 2007; 2009).

At all stations, the $C$. migratorius distribution was at depths ranging from 50 to $350 \mathrm{~m}$. At a depth of less than $200 \mathrm{~m}$, there were active vertical movements of fish (Fig. 4a). Some specimens made vertical movements for 13-15 $\mathrm{m}$ in 2-3 minutes. In the morning, during the dawn, there was a redistribution of fish aggregations from depths of $80-115$ to $125-175 \mathrm{~m}$, i.e. their migration rate was approximately $50 \mathrm{~m}$ in 40 minutes. Fish found at a depth of more than $200 \mathrm{~m}$ showed passive behaviour: they remained for a long time in the impulse volume at a constant depth. In addition, occasionally, there were separate dense aggregations of C. migratorius at depths of 50-100 m (Fig. 4b).
Table 1. Characteristics of the stations, March 2018

\begin{tabular}{|c|c|c|c|}
\hline Station No. & Latitude & Longitude & Depth, m \\
\hline 1 & $51^{\circ} 49^{\prime}$ & $104^{\circ} 53^{\prime}$ & 388 \\
2 & $51^{\circ} 47^{\prime}$ & $104^{\circ} 56^{\prime}$ & 1396 \\
3 & $51^{\circ} 45^{\prime}$ & $104^{\circ} 58^{\prime}$ & 1417 \\
4 & $51^{\circ} 35^{\prime}$ & $105^{\circ} 06^{\prime}$ & 570 \\
5 & $51^{\circ} 34^{\prime}$ & $105^{\circ} 06^{\prime}$ & 390 \\
\hline
\end{tabular}

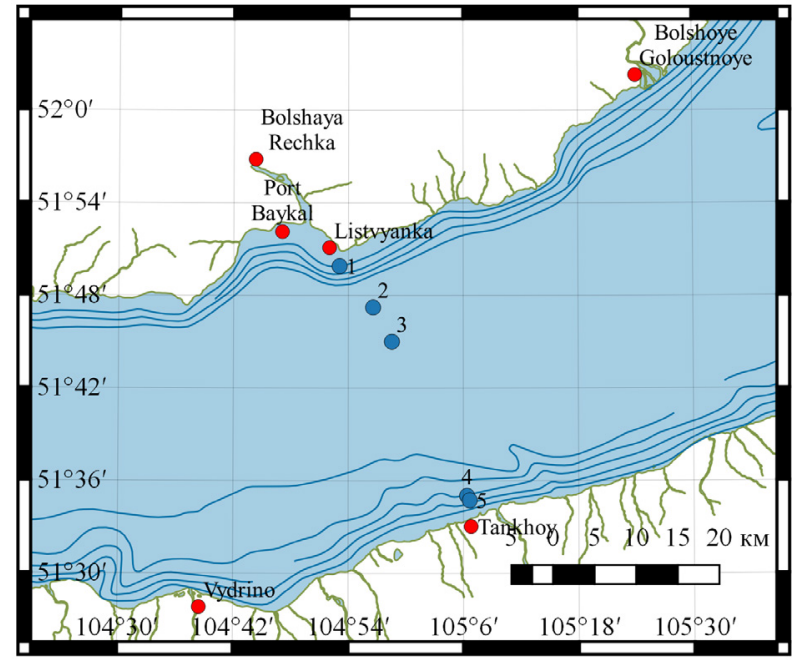

Fig.1. Map of the area of the experiment points with the hydroacoustic record

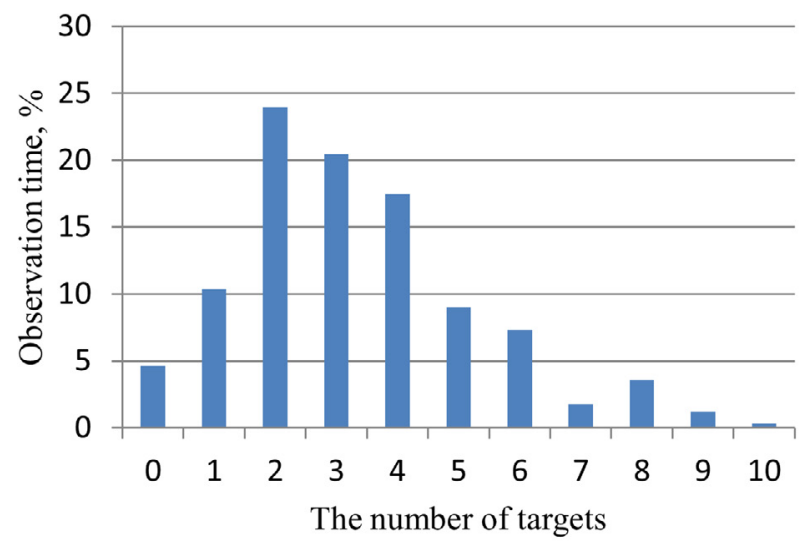

Fig.2. Observation time of the number of targets in the sonar beam

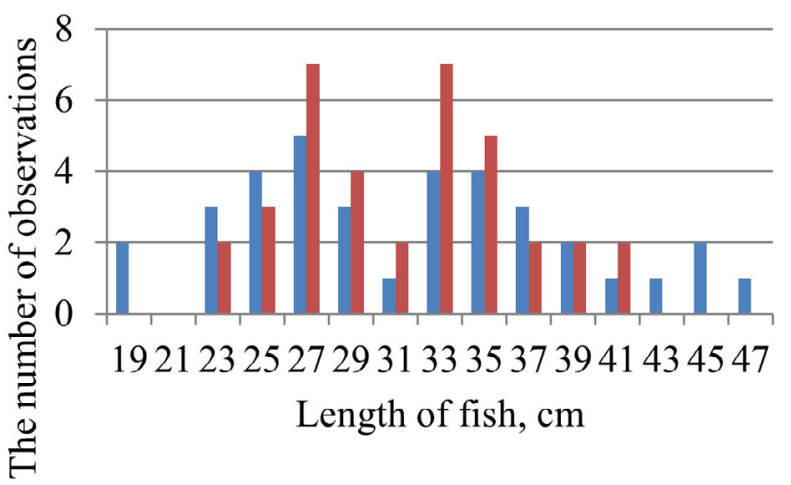

च $\mathrm{TS}=20^{*} \log (\mathrm{L})-63,45$ (Makarov et al., 2018)

चS $=78 * \log (\mathrm{L})-76.4$ (Kudryavtsev et al., 2005)

Fig.3. Length structure of $C$. migratorius reconstructed from the TS 

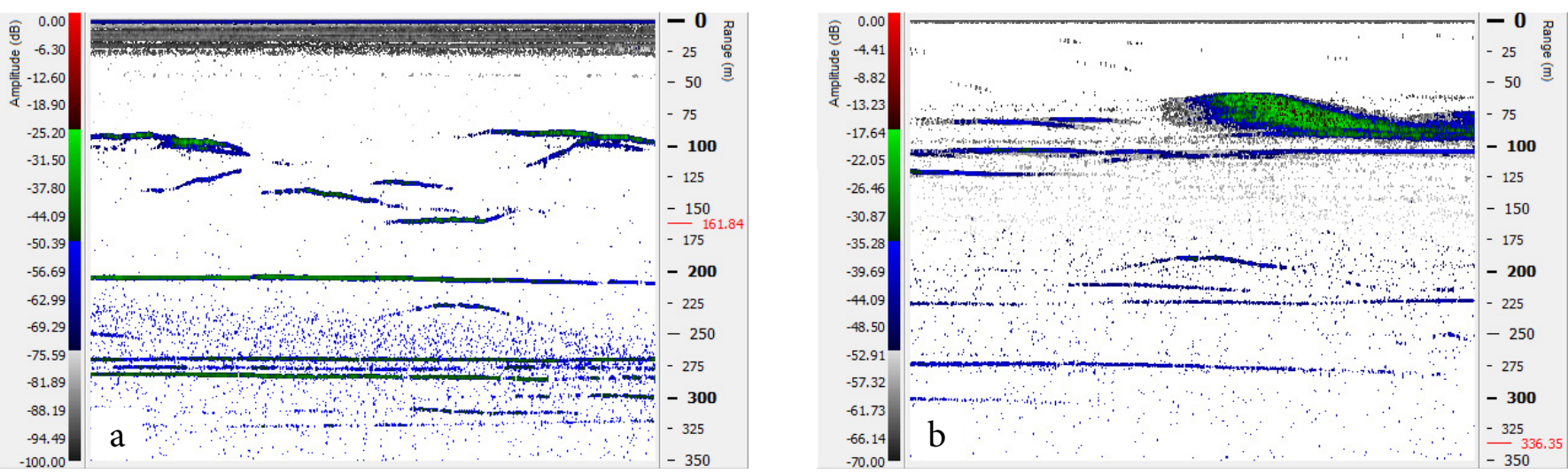

Fig.4. Echograms of sound-scattering layers indicating the C. migratorius recording of:

a) single specimens and b) single specimens and aggregation

Based on the obtained results, we can assume that C. migratorius simultaneously executes three behavioural strategies during the winter period:

- resting at a depth of more than $200 \mathrm{~m}$;

- vertical food migrations;

- schooling behaviour with horizontal migrations and active search for aggregated food objects.

The resting state is similar to the behaviour of fish in river wintering hols and fish wintering in the deep part of limnic-type water bodies, when energy expenditures are minimum. This state corresponds to the resting phase, showing the lack of fish responses to food signals. This phase occurs in fish after a period of active feeding, when a specimen reaches a certain nutritional state (Pavlov and Kasumyan, 1998). The resting phase in fish can be associated with a certain physiological state, time of day or season.

The other two strategies correspond to the phase of the search for food or searching behaviour. Significant changes in the behaviour, which are evident in many fish species, accompany this phase. Vertical migrations are the subphase of the near search, whereas horizontal ones - the distant search (Pavlov and Kasumyan, 1998).

The model of vertical migrations for food is typical of a number of marine fish species and fish found in deep lakes. Vertical migrations of fish are associated with the change in the volume of the swim bladder. Thus, the change in depth by $10 \mathrm{~m}$ changes the pressure by one atmosphere. The ascent of fish by $15 \mathrm{~m}$ from a depth of $100 \mathrm{~m}$ increases the bladder volume by $15 \%$. Thereafter, C. migratorius should release the excessive gas or return to the optimum depth. Releasing gas from the swim bladder is possible due to its anatomical connection with the oesophagus. During the migration by $50 \mathrm{~m}$ deeper, fish must secrete gas into the swim bladder in an amount equivalent to five volumes of the bladder under standard conditions (1 atm pressure at a temperature of $0^{\circ} \mathrm{C}$ ) in order to maintain the neutral buoyancy. Hence, vertical migrations are associated with additional energy expenditures. Releasing gases from the swim bladder during ascent to the upper horizons and maintaining its volume during the migration downwards is also typical of other coregonid fish inhabiting relatively deep water bodies, including Coregonus lavaretus (Linnaeus, 1758) and Coregonus albula (Linnaeus, 1758) (Knudsen and Gjelland, 2004). Effective pressure regulating mechanisms in

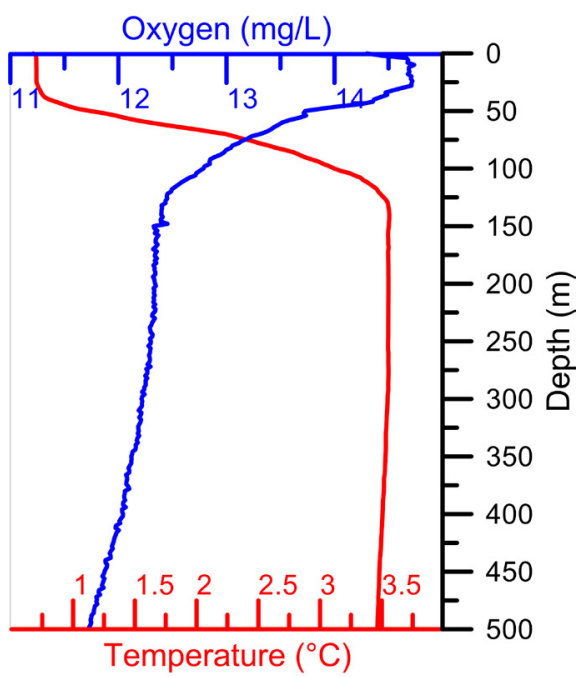

Fig.5. Change in temperature and oxygen concentration, 28 March 2018

the swim bladder are one of the important adaptive characteristics that enabled $C$. migratorius to migrate over a wide range of depths and occupy a dominant position among all Baikal fishes with a swim bladder. $C$. migratorius inhabits oligotrophic water bodies at depths of 0-350 $\mathrm{m}$. The oxygen concentration in the lake up to the maximum depths $(1636 \mathrm{~m})$ is favourable for all fish species, including the under-ice period. During the study period, its concentration varied from $14.5 \mathrm{mg} / \mathrm{l}$ in the surface level to $11.5 \mathrm{mg} / \mathrm{l}$ at a depth of $500 \mathrm{~m}$ (Fig. 5 ). The temperature distribution with the occurrence of thermocline at depths of 25-125 m was typical of the winter (Fig. 5). There were active movements of fish in the layer of the temperature jump, below which, in the waters with a temperature of maximum density, the specimens showed passive behaviour.

The distant search for food occurs when the local aggregations of food organisms form in a water body. In Lake Baikal, the periodic occurrence of omul schools in shallow areas is well known, which is used in winter amateur fishing.

In winter and early spring, the main part of the $C$. migratorius inhabits the slope zone of the lake adjacent to the main fishing areas, i.e. deltas and estuaries of spawning rivers (Kozhov, 1954; Smirnov and Shumilov, 1974; Melnik et al., 2009). The early winter distribution (January-February) of $C$. migratorius was investigated using gillnets. At depths of 150-300 
$\mathrm{m}$, there were dense aggregations. Winter net catches were mostly used to study nutrition and nutritional relationships of $C$. migratorius in the fishing areas. To date, the winter structure of the omul population in the pelagic zone of the lake has been poorly studied due to low fish aggregations in this area and a laborious setting of multi-mesh gillnets at different depths from 50 to $350 \mathrm{~m}$, with a setting duration of two-three days. The hydroacoustic method allows the real-time observations of the changes in the fish aggregation and distribution as well as obtaining the representative data on the intensity of the return signal, which, unlike gillnets, are free of dimensional selectivity.

The results of our studies have shown the nature of the winter distribution of $C$. migratorius, which also persist in the early spring, immediately after the ice melting. The previous data on the spring net and hydroacoustic surveys showed the two-layer distribution of $C$. migratorius in the water column of the lake (in water layers of 50-150 and 160-350 m), which was due to the morpho-ecological intraspecific differentiation of fish (Sideleva et al., 1996; Smirnova-Zalumi et al., 2007; Melnik et al., 2009). Dense $C$. migratorius aggregations indicating the horizontal migrations in open waters also occurred mainly at depths of 50-100 m during the ice cover breakup and the subsequent spring warming of the coastal and surface waters in Baikal (Melnik et al., 2009). Our data have confirmed the results of these studies and, additionally, indicated that the behaviour of the specimens inhabiting upper and lower horizons differs significantly.

\section{Conclusions}

The hydroacoustic recording of fish in the monostatic mode from the ice cover of Lake Baikal has allowed us to obtain new data on the characteristics of distribution and behaviour of C. migratorius. Observations of the C. migratorius behaviour in the winter using hydroacoustic method can be useful for the future studies of the characteristics of different fish behavioural and nutritional models, the structure of populations inhabiting various zones of the lake, etc. The obtained results optimize the technology of test fishing in winter based on the vertical distribution and behavioural characteristics of C. migratorius. Considering the selectivity of nets, their synchronous use the hydroacoustic method can significantly complement the information about the dimensional characteristics of fish. This approach, as a basis of the quantitative method of automatic recording of individual behavioural acts and changes in the fish aggregations, together with the use of hydrophysical equipment can show the response of fish to the changes in certain environmental parameters.

\section{Acknowledgements}

The work was performed within the project No.

\section{References}

Brehmer P., Sarré A., Guennegan Y. et al. 2019. Vessel avoidance response: a complex tradeoff between fish multisensory integration and environmental variables. Reviews in Fisheries Science \& Aquaculture 27: 380-391. DOI: 10.1080/23308249.2019.1601157

Dzyuba E.V., Bogdanov B.E., Sapozhnikova Yu.P. et al. 2018. Promising ichthyologic studies in Lake Baikal: fundamental and applied aspects. Limnology and Freshwater Biology 1: 28-31. DOI: 10.31951/2658-3518-2018-A-1-28

Engas A., Gødo O.R., Jørgensen T. 2000. A comparison between vessel and trawl tracks as observed by the ITI trawl instrumentation. Fisheries Research 45: 297-301. DOI: 10.1016/S0165-7836(99)00123-X

Gerlotto F., Fréon P. 1992. Some elements on vertical avoidance of fish schools to a vessel during acoustics surveys. Fisheries Research 14: 251-259. DOI: 10.1016/0165-7836(92)90035-R

Knudsen F.R., Gjelland K.Ø. 2004. Hydroacoustic observations indicating swimbladder volume compensation during the diel vertical migration in coregonids (Coregonus lavaretus and Coregonus albula). Fisheries Research 66: 337-341. DOI: 10.1016/S0165-7836(03)00191-7

Kozhov M.M. 1954. Vertical distribution of plankton feeding fish of Lake Baikal. Journal of Ichthyology 2: 7-20. (in Russian)

Lucas M.C., Baras E. 2000. Methods for studying spatial behaviour of freshwater fishes in the natural environment. Fish \& Fisheries 1: 283-316. DOI: 10.1046/j.1467-2979.2000.00028.x

Makarov M.M., Degtev A.I., Khanaev I.V. et al. 2018. Experimental studies for measuring the target strength of the Baikalian omul at the frequency of $200 \mathrm{khz}$. International Journal of Applied and Fundamental Research 2: 142-146. DOI: $10.17513 /$ mjpfi. 12124

Melnik N.G., Degtyarev V.A., Dzyuba E.V. et al. 2007. Distribution of Baikal omul (Coregonus autumnalis migratorius) during the 2003 acoustic survey. Advances in Limnology 60: 231-236.

Melnik N.G., Smirnova-Zalumi N.S., Smirnov V.V. et al. 2009. Hydroacoustic survey of baikal omul. Novosibirsk: Nauka. (in Russian)

Sideleva V.G., Smirnov V.V., Smirnova-Zalumi N.S. et al. 1996. The assessment of the stocks of the Baikal omul using a hydroacoustic method. Rybnoye Khozyaistvo [Fisheries] 6: 37-38. (in Russian)

Smirnov V.V., Shumilov I.P. 1974. Baikal Omul. Novosibirsk: Nauka. (in Russian)

Smirnova-Zalumi N.S., Melnik N.G., Smirnov V.V. et al. 2007. Seasonal distribution of omul (Coregonus autumnalis migratorius (Georgi)) in Lake Baikal: implications for acoustics assessment. Advances in Limnology 60: 237-246.

Kaplina G.S. 1974. Macrozoobenthos of stony soils from the littoral zone of Lake Baikal and its seasonal dynamics (the 1963-1968 data, the Bolshiye Koty area). In: Kozhova O.M. (Ed.), The productivity of Lake Baikal and anthropogenic changes in its nature. Irkutsk, pp. 126-137. (in Russian)

Kudryavtsev V.I., Degtev A.I., Sokolov A.V. 2005. On the peculiarities of quantitative assessment of the stocks of the Baikal omul using a hydroacoustic method. Rybnoye Khozyaistvo [Fisheries] 3: 66-69. (in Russian)

Pavlov D.S., Kasumyan A.O. 1998. The structure of nutritional behaviour. Voprosy Ichtiologii [Journal of Ichthyology] 38: 123-136. (in Russian) 